\title{
Outcomes of pulmonary endarterectomy for treatment of extreme thromboembolic pulmonary hypertension
}

\author{
Patricia A. Thistlethwaite, MD, PhD, Aaron Kemp, BA, Lingling Du, MD, Michael M. Madani, MD, and \\ Stuart W. Jamieson, MB, FRCS
}

Earn CME credits at http://cme.ctsnetjournals.org
From the Division of Cardiothoracic Surgery, University of California, San Diego, San Diego, Calif.

Supported by National Institutes of Health grant R01-HL70852 (P.A.T.)

Read at the Thirty-first Annual Meeting of The Western Thoracic Surgical Association, Victoria, BC, Canada, June 22-25, 2005.

Received for publication May 18, 2005; revisions received July 15, 2005; accepted for publication July 19, 2005 .

Address for reprints: Patricia A. Thistlethwaite, MD, PhD, Division of Cardiothoracic Surgery, University of California, San Diego, San Diego, CA 92103-8892 (Email: pthistlethwaite@ucsd.edu).

J Thorac Cardiovasc Surg 2006;131:307-13

$0022-5223 / \$ 32.00$

Copyright () 2006 by The American Association for Thoracic Surgery

doi:10.1016/j.jtcvs.2005.07.033
Objective: Pulmonary endarterectomy is the operation of choice for thromboembolic pulmonary hypertension. As the largest referral center for thromboembolic pulmonary hypertension in the world, we are frequently asked whether patients with extreme pulmonary hypertension (pulmonary artery systolic pressure $>100 \mathrm{~mm} \mathrm{Hg}$ ) can safely undergo this operation with therapeutic benefit.

Methods: To determine whether patients with pulmonary artery systolic pressures of greater than $100 \mathrm{~mm} \mathrm{Hg}$ have favorable outcomes after pulmonary endarterectomy, we reviewed the outcomes of 743 patients who underwent this operation between 1999 and 2004. We compared hemodynamic and outcome parameters of 65 patients (group 1: 26 male and 39 female patients; mean age, 49.5 years) who had preoperative pulmonary artery systolic pressures of greater than $100 \mathrm{~mm} \mathrm{Hg}$ with 678 patients (group 2: 314 male and 364 female patients; mean age, 50.3 years) with preoperative pulmonary artery systolic pressures of less than $100 \mathrm{~mm} \mathrm{Hg}$.

Results: Group 1 patients had a greater overall diminution in pulmonary vascular resistance (mean decrease: $926.7 \pm 511.1$ vs $546.4 \pm 365.1$ dynes $\cdot \mathrm{sec} \cdot \mathrm{cm}^{-5}, P<$ .01 ) and reduction in pulmonary artery systolic pressure (mean decrease: $50.5 \pm$ 18.7 vs $27.2 \pm 18.6 \mathrm{~mm} \mathrm{Hg}, P<.05$ ), with similar improvement in cardiac output (mean increase: $1.53 \pm 1.47$ vs $1.55 \pm 1.58 \mathrm{~L} / \mathrm{min}$ ) compared with values seen in group 2 patients. Although length of hospital stay was similar for the 2 groups, overall perioperative survival was slightly lower in group 1 patients $(89.2 \%$ [58/65] for group 1 vs $96.5 \%$ [654/678] for group 2). Patients with extreme pulmonary hypertension manifest a higher rate of postoperative reperfusion edema, leading to longer days of intubation compared with group 2 patients.

Conclusions: Pulmonary endarterectomy can be performed safely in patients with severe thromboembolic pulmonary hypertension. The magnitude of preoperative pulmonary artery systolic pressure or pulmonary vascular resistance is not a contraindication for surgical intervention. Indeed, patients with extreme pulmonary hypertension might benefit the most from this operation.

$\mathrm{P}$ ulmonary hypertension resulting from chronic thromboembolic disease to the lung or recurrent unresolved pulmonary emboli is well known to be a poor prognostic factor for long-term survival and is a cause of significant patient morbidity. ${ }^{1}$ Indeed, survival of patients with pulmonary hypertension is inversely related to the magnitude of pulmonary artery systolic pressure and pulmonary vascular resistance. ${ }^{2}$ Pulmonary endarterectomy is the operation of choice for treatment of chronic thromboembolic disease to the lung. We and others have shown that pulmonary endarterectomy ameliorates pulmonary hypertension by improving lung ventilation-perfusion match, arresting right ventricular dysfunction and tricuspid regurgitation, limiting retrograde extension of clot obstruction, and preventing arteriopathic changes in the remaining patent small pulmonary vessels. ${ }^{3,4}$ 


\section{Abbreviations and Acronyms \\ ICU = intensive care unit \\ NYHA $=$ New York Heart Association}

A subset of patients with thromboembolic pulmonary hypertension present for surgical intervention with an extreme form of this disease, with pulmonary artery systolic pressures in excess of $100 \mathrm{~mm} \mathrm{Hg}$ and often in excess of systemic pressures. Although previous case reports and small series have suggested that this population of patients has a poor outcome after pulmonary endarterectomy, ${ }^{5-7}$ no large study has addressed whether these patients actually benefit from this operation with acceptable perioperative mortality and morbidity. This study was designed as a prospective analysis of patients undergoing isolated pulmonary endarterectomy at our institution over a 5-year period to examine outcomes in patients with preoperative pressures exceeding $100 \mathrm{~mm} \mathrm{Hg}$, with the goal of determining whether candidacy for this operation should be limited to those patients with less extreme forms of disease.

\section{Methods}

\section{Patient Selection}

We identified and followed all patients who underwent isolated pulmonary endarterectomy from July 1999 through July 2004 at our institution. This included 743 patients (340 male and 403 female patients; mean age, 50.2 years; range, 8.9-83.9 years) who comprise the most recent data set of the University of California, San Diego Pulmonary Endarterectomy Registry. Patients undergoing concomitant coronary revascularization or valve repairreplacement at the time of pulmonary endarterectomy were excluded from this study. The selection criteria for this operation included the following: (1) pulmonary hypertension with evidence of thromboembolic disease on pulmonary angiography, (2) pulmonary vascular resistance of greater than 300 dynes $\cdot \mathrm{sec} \cdot \mathrm{cm}^{-5}$, and (3) absence of significant noncardiac comorbid disease. For data analysis, patients were divided into 2 groups: group 1 included patients with pulmonary artery systolic pressures exceeding $100 \mathrm{~mm} \mathrm{Hg}$ (65 patients total; 26 male and 39 female patients; mean age, 49.5 years), and group 2 included patients with pulmonary artery systolic pressures of less than $100 \mathrm{~mm} \mathrm{Hg}$ (678 patients total; 314 male and 364 female patients; mean age, 50.3 years).

According to the usual practice at our institution, all patients underwent transthoracic echocardiography and preoperative pulmonary angiography. Measurement of tricuspid regurgitant velocity was performed in parasternal, apical, and subcostal imaging positions by using continuous-wave Doppler interrogation, as previously described. ${ }^{8,9}$ Confirmatory blind Doppler assessment of peak TR velocity with a Pedoff continuous-wave probe was also performed in all patients. Patients older than 45 years underwent preoperative coronary angiography. Before the operation, Greenfield vena caval filters were placed in all patients.

\section{Operative Techniques and Hemodynamic Measurement}

Our surgical method of pulmonary endarterectomy has been previously described. ${ }^{10}$ Three surgeons performed all operations on cardiopulmonary bypass, with a period of circulatory arrest ranging from 3 minutes to 76 minutes (mean, 35.7 minutes) for the distal-most portion of the endarterectomy procedure for both lungs. Preoperative hemodynamics were assessed 14 months to 1 day (mean time, 2.3 days; median time, 3 days) before the operation by means of right-sided heart catheterization (group 1, 62 patients on an elective outpatient basis and 3 patients on an urgent inpatient basis; group 2, 667 patients on an elective outpatient basis and 11 patients on an urgent inpatient basis). Postoperative hemodynamic measurements were made, with each patient weaned from inotropic and vasodilator support before Swan-Ganz line (Edwards Lifesciences, Irvine, Calif) removal 1 to 22 days (mean, 2.3 days) after the operation.

\section{Statistical Methods}

Results are summarized as means \pm standard deviation or number (percentage). $\chi^{2}$ Tests were performed to test for statistical significance for variables measured by frequency, such as the number of patients in the intensive care unit (ICU) before surgical intervention. Unpaired Student $t$ tests were performed to identify significant changes in hemodynamic and other variables within the 2 groups. All Student $t$ tests were 2-sided. Software used for the data and statistical analyses included S-Plus 6.2 (Insightful Corporation, Seattle, Wash) and PATS 4.0 (Axis Clinical Software Inc, Portland, Ore).

\section{Results}

All 743 patients in this study underwent bilateral pulmonary endarterectomy. Characteristics at the time of the operation for patients with pulmonary artery pressures of greater than $100 \mathrm{~mm} \mathrm{Hg}$ (group 1) and patients with pulmonary artery pressures of less than $100 \mathrm{~mm} \mathrm{Hg}$ (group 2) are detailed in Table 1. The 2 patient groups were similar with respect to age and sex. The severity of disease in patients with preoperative pulmonary artery pressures exceeding $100 \mathrm{~mm} \mathrm{Hg}$ was reflected in presurgical hemodynamic and echocardiographic measurements. As seen in Table 1, patients in group 1 had significant increases in pulmonary artery diastolic pressures, pulmonary vascular resistance, and degree of tricuspid regurgitant velocity compared with group 2 patients before operative intervention. In addition, group 1 patients had a higher percentage of individuals requiring hospitalization, being treated in the ICU, and requiring inotropic support before the operation compared with group 2 patients. Patients with pulmonary artery systolic pressures exceeding $100 \mathrm{~mm} \mathrm{Hg}$ had relatively higher percentages of New York Heart Association (NYHA) functional class III and IV symptoms compared with patients with pulmonary artery pressures of less than $100 \mathrm{~mm} \mathrm{Hg}$. (96.9\% NYHA class III/IV in group 1 compared with $86.5 \%$ NYHA Class III/IV in group 2). Group 1 and group 2 were similar with respect to the proportion of patients who had a documented 
TABLE 1. Preoperative patient characteristics

\begin{tabular}{|c|c|c|c|c|}
\hline Variable & $\begin{array}{l}\text { All patients } \\
(n=743)\end{array}$ & $\begin{array}{c}\text { Group 1: PAS }>100 \mathrm{~mm} \mathrm{Hg} \\
(\mathrm{n}=65)\end{array}$ & $\begin{array}{c}\text { Group 2: PAS }<100 \mathrm{~mm} \mathrm{Hg} \\
(n=678)\end{array}$ & $P$ value* \\
\hline Age (y) & $50.2 \pm 14.9$ & $49.5 \pm 15.4$ & $50.3 \pm 14.9$ & .489 \\
\hline Male sex $(\%)$ & $340(45.8)$ & $26(40.0)$ & $314(46.3)$ & \\
\hline \multicolumn{5}{|l|}{ Pulmonary artery pressure $(\mathrm{mm} \mathrm{Hg})$} \\
\hline Systolic & $76.2 \pm 18.1$ & $108.1 \pm 8.4$ & $73.2 \pm 15.7$ & .002 \\
\hline Diastolic & $29.3 \pm 9.8$ & $40.8 \pm 8.8$ & $28.2 \pm 9.2$ & .049 \\
\hline Pulmonary vascular resistance (dynes $\cdot \mathrm{sec} \cdot \mathrm{cm}^{-5}$ ) & $873.6 \pm 439.7$ & $1299.0 \pm 532.6$ & $832.5 \pm 407.2$ & .002 \\
\hline Cardiac output (L/min) & $3.9 \pm 1.4$ & $3.6 \pm 1.3$ & $4.0 \pm 1.4$ & .224 \\
\hline Pulmonary capillary wedge pressure $(\mathrm{mm} \mathrm{Hg})$ & $9.3 \pm 4.6$ & $10.5 \pm 4.7$ & $9.2 \pm 4.6$ & .477 \\
\hline Tricuspid regurgitant jet (M/s) & $4.2 \pm 0.7$ & $4.8 \pm 0.7$ & $4.2 \pm 0.7$ & .444 \\
\hline In hospital $>24 \mathrm{~h}$ preoperatively & $166(22.3)$ & $26(40.0)$ & $140(20.6)$ & .001 \\
\hline In ICU preoperatively & $12(1.6)$ & $6(9.2)$ & $6(0.9)$ & $<.001$ \\
\hline On intravenous inotropes preoperatively & $8(1.1)$ & $2(3.1)$ & $6(0.9)$ & .102 \\
\hline Mechanical ventilation preoperatively & $5(0.7)$ & $3(4.6)$ & $2(0.3)$ & $<.001$ \\
\hline \multicolumn{5}{|l|}{ NYHA class } \\
\hline I & $0(0)$ & $0(0)$ & $0(0)$ & \\
\hline II & $94(12.7)$ & $2(3.0)$ & $92(13.5)$ & \\
\hline III & $590(79.4)$ & $53(81.5)$ & $537(79.2)$ & \\
\hline IV & $59(7.9)$ & $10(15.4)$ & $49(7.3)$ & \\
\hline
\end{tabular}

Data are shown as means \pm standard deviation or number (percentage). PAS, Pulmonary artery systolic pressure; ICU, intensive care unit; NYHA, New York Heart Association. $* P$ value compares groups 1 and 2.

history of deep venous thrombosis (group 1: 25/65 [38.5\%] patients vs group 2: $295 / 678$ [43.5\%] patients) and to the proportion of patients who had a documented history of pulmonary embolism (group 1: 44/65 [67.7\%] patients vs group 2: 468/678 [69.0\%] patients).

In-hospital survival for all for patients with pulmonary artery pressures exceeding $100 \mathrm{~mm} \mathrm{Hg}$ was $89.2 \%$ (58/65 patients). Overall survival in this patient group was lower than survival in patients with pulmonary artery pressures of less than $100 \mathrm{~mm} \mathrm{Hg}$ treated during the same time period (96.5\% [654/678] patients). There were no significant differences between group 1 and group 2 patients with respect to cardiopulmonary bypass time, crossclamp time, or circulatory arrest time (Figure 1). Total cardiopulmonary bypass time correlated with body mass and cooling-rewarming intervals and not with specific preoperative hemodynamic parameters.

Table 2 presents the mean change between preoperative and postoperative hemodynamic parameters of pulmonary artery pressure, pulmonary vascular resistance, and cardiac output among the 2 patient groups. Postoperative hemodynamic measurements were made with the patients weaned from all inotropic and vasodilator support just before SwanGanz line removal. There was a significant difference between the mean diminution in pulmonary artery systolic pressure and the mean diminution in pulmonary vascular resistance measured for patients in groups 1 and 2. Patients with preoperative pulmonary artery pressures exceeding $100 \mathrm{~mm} \mathrm{Hg}$ had similar improvement in cardiac output after surgical intervention compared with that seen in patients with preoperative pulmonary artery pressures of less than $100 \mathrm{~mm} \mathrm{Hg}$. Improvement in tricuspid regurgitation status, quantitated by reduction in tricuspid regurgitant jet velocity, occurred in greater than $97 \%$ of individuals in both groups after surgical intervention, as measured with predischarge transthoracic echocardiography.

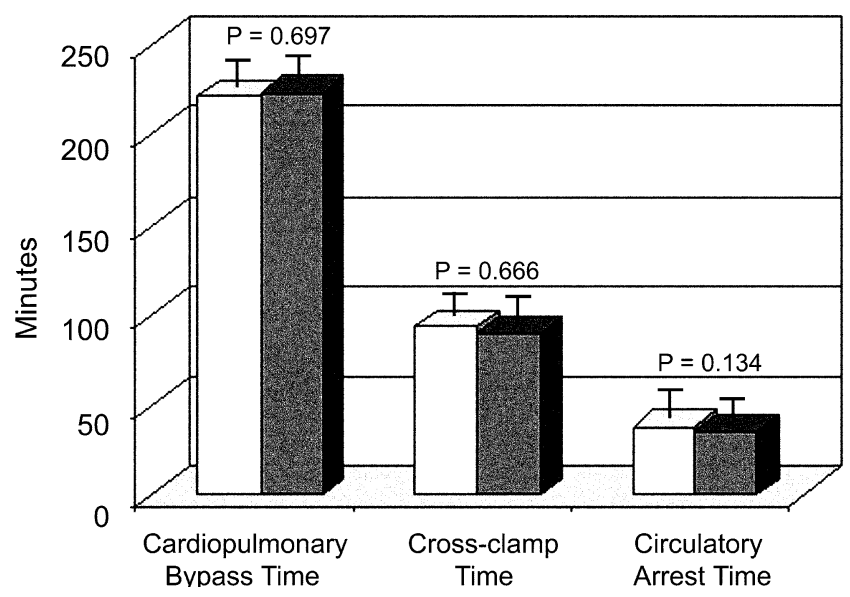

Figure 1. Comparison of cardiopulmonary bypass, crossclamp, and circulatory arrest times in patients undergoing pulmonary endarterectomy. Open bar, Patients with pulmonary artery systolic pressures of greater than $100 \mathrm{~mm} \mathrm{Hg}$; filled bar, patients with pulmonary artery systolic pressures of less than $100 \mathrm{~mm} \mathrm{Hg}$. 
TABLE 2. Comparison of perioperative hemodynamic parameters

\begin{tabular}{|c|c|c|c|c|}
\hline Variable & $\begin{array}{l}\text { All patients } \\
\text { (n }=743)\end{array}$ & $\begin{array}{c}\text { Group 1: PAS }>100 \mathrm{~mm} \mathrm{Hg} \\
(\mathrm{n}=65)\end{array}$ & $\begin{array}{c}\text { Group 2: PAS }<100 \mathrm{~mm} \mathrm{Hg} \\
(\mathrm{n}=678)\end{array}$ & $P$ value* \\
\hline Mean decrease in PAS $(\mathrm{mm} \mathrm{Hg})$ & $29.1 \pm 19.7$ & $50.5 \pm 18.7$ & $27.2 \pm 18.6$ & .040 \\
\hline Mean decrease in PAD (mm $\mathrm{Hg})$ & $10.4 \pm 10.3$ & $19.3 \pm 10.3$ & $9.6 \pm 9.9$ & .467 \\
\hline Mean decrease in PVR (dynes $\cdot \mathrm{sec} \cdot \mathrm{cm}^{-5}$ ) & $577.6 \pm 393.8$ & $926.7 \pm 511.1$ & $546.4 \pm 365.1$ & .002 \\
\hline Mean increase in $\mathrm{CO}(\mathrm{L} / \mathrm{min})$ & $1.54 \pm 1.57$ & $1.53 \pm 1.47$ & $1.55 \pm 1.58$ & .500 \\
\hline Mean decrease in tricuspid regurgitant velocity $(\mathrm{M} / \mathrm{s})$ & $1.16 \pm 0.80$ & $1.86 \pm 0.84$ & $1.11 \pm 0.78$ & .492 \\
\hline
\end{tabular}

Data are shown as means \pm standard deviation. PAS, Pulmonary artery systolic pressure; $P A D$, pulmonary artery diastolic pressure; $P V R$, pulmonary vascular resistance; $C O$, cardiac output. $* P$ value compares groups 1 and 2 .

Group 1 patients manifest longer mean and median periods of intubation (mean, 7.4 days; median, 3 days) compared with group 2 patients (mean, 3.7 days; median, 1.0 days; Table 3). This led to longer ICU stays for group 1 patients (mean, 9.5 days; median, 6.0 days) compared with those for group 2 patients (mean, 6.0 days; median, 4.0 days). In general, after pulmonary endarterectomy, the patients requiring longer periods of intubation did so because of reperfusion edema after opening of blocked vascular beds, perioperative pneumonia, or both. With longer periods of intubation and ICU stays, patients in group 1 had overall hospital stays that were slightly longer than those of patients in group 2, although this did not achieve statistical significance (group 1 mean length of hospital stay, 18.1 days [median, 14.0 days]; group 2 mean length of hospital stay, 14.5 days [median, 12.0 days]).

Although patients with pulmonary artery systolic pressures of greater than $100 \mathrm{~mm} \mathrm{Hg}$ had favorable outcome with respect to survival, they had a higher incidence of respiratory-related postoperative complications compared with patients with pulmonary artery systolic pressures of less than $100 \mathrm{~mm} \mathrm{Hg}$ (Table 4). Reperfusion edema necessitating prolonged mechanical ventilation was the most common perioperative complication for both groups but occurred with greater frequency in those patients who had preoperative pulmonary artery systolic pressures of greater than $100 \mathrm{~mm} \mathrm{Hg}$ (group 1: 13/65 [20.0\%] patients; group 2: 49/678 [7.3\%] patients).

Whereas $96 \%$ of patients undergoing pulmonary endarterectomy for extreme pulmonary hypertension were in NYHA functional class III or IV before surgical intervention, at the time of discharge, $80.0 \%$ of patients were assessed to be in NYHA functional class I or II. These results were similar to improvement seen in patients undergoing pulmonary endarterectomy who had lower $(<100$ $\mathrm{mm} \mathrm{Hg}$ ) pulmonary artery systolic pressures. Most (86.5\%) of these patients were in NYHA functional class III or IV before surgical intervention, with $95.2 \%$ of the same cohort in NYHA functional class I or II at the time of discharge.

\section{Discussion}

Pulmonary hypertension caused by chronic thromboembolic disease is associated with poor long-term survival. ${ }^{11,12}$ In the last 15 years, our group has performed more than 1880 pulmonary endarterectomies, with perioperative survival approaching $4.4 \% .^{13}$ As time has progressed, the technical hurdles of this operation have been surmounted. However, despite overall favorable outcomes of pulmonary endarterectomy for thromboembolic disease, there has been little systematic evaluation of preoperative variables to determine which of these have the greatest effect on postoperative outcome. To date, the only factor found useful in predicting outcome after pulmonary endarterectomy in a large series has been intraoperative location of thromboembolic disease. ${ }^{14}$ Smaller series of less than 35 patients have suggested that pulmonary arterial occlusion pressure waveform analysis ${ }^{15}$ and quantitation of plasma brain natriuretic peptide $^{16}$ might also be useful in predicting surgical outcome.

One of the unresolved problems in the treatment of chronic thromboembolic disease is the accurate determination of which subset of patients would be best suited to surgical intervention. Because of increased awareness of thromboembolic pulmonary hypertension, several centers around the world are now reporting results of pulmonary endarterectomy for small series of patients with this disease. ${ }^{17-20}$ Collectively, however, the surgical community

TABLE 3. Postoperative outcome

\begin{tabular}{lccc}
\hline & $\begin{array}{c}\text { All patients } \\
\text { (n = 743) }\end{array}$ & $\begin{array}{c}\text { Group 1: PAS } \\
>\mathbf{1 0 0} \mathbf{~ m m ~ H g} \\
\text { (n = 65) }\end{array}$ & $\begin{array}{c}\text { Group 2: PAS } \\
<\mathbf{1 0 0 ~} \mathbf{~ m m ~ H g} \\
\text { (n = 678) }\end{array}$ \\
\hline $\begin{array}{l}\text { Mean/median days } \\
\text { intubated }\end{array}$ & $4.0 / 1.0$ & $7.4 / 3.0$ & $3.7 / 1.0$ \\
$\begin{array}{l}\text { Mean/median days } \\
\text { in ICU }\end{array}$ & $6.3 / 4.0$ & $9.5 / 6.0$ & $6.0 / 4.0$ \\
$\begin{array}{l}\text { Mean/median days } \\
\text { in hospital }\end{array}$ & $14.9 / 12.0$ & $18.1 / 14.0$ & $14.5 / 12.0$ \\
$\begin{array}{l}\text { Mortality (\%) } \\
\text { Mon }\end{array}$ & $31(4.2)$ & $7(10.8)$ & $24(3.5)^{*}$
\end{tabular}

PAS, Pulmonary artery systolic pressure; $I C U$, intensive care unit. $* P<.01$ for comparing groups 1 and 2 . 
TABLE 4. Perioperative morbidity

\begin{tabular}{|c|c|c|}
\hline Complication & $\begin{array}{c}\text { Group 1: PAS } \\
>100 \mathrm{~mm} \mathrm{Hg} \\
\text { (n=65), no. of } \\
\text { patients }(\%)^{*}\end{array}$ & $\begin{array}{c}\text { Group 2: PAS } \\
<100 \mathrm{~mm} \mathrm{Hg} \\
\text { (n=678), no. of } \\
\text { patients }(\%)^{*}\end{array}$ \\
\hline Reperfusion edema & $13(20.0)$ & $47(6.9)$ \\
\hline Pneumonia & $9(13.9)$ & $24(3.5)$ \\
\hline Reoperative bleeding & $3(4.6)$ & $18(2.7)$ \\
\hline Atrial fibrillation & $2(3.1)$ & $13(1.9)$ \\
\hline Acute renal failure & $2(3.1)$ & $4(0.6)$ \\
\hline Tracheostomy & $2(3.1)$ & $10(1.5)$ \\
\hline $\begin{array}{l}\text { Sternal wound } \\
\text { infection }\end{array}$ & $1(1.5)$ & $14(2.1)$ \\
\hline Hemothorax & $1(1.5)$ & $2(0.3)$ \\
\hline Pneumothorax & 0 & $9(1.3)$ \\
\hline Chylothorax & 0 & $3(0.4)$ \\
\hline Pleural effusion & 0 & $1(0.1)$ \\
\hline Pericardial effusion & 0 & $7(1.0)$ \\
\hline $\begin{array}{l}\text { Femoral-retroperitoneal } \\
\text { hematoma }\end{array}$ & 0 & $3(0.4)$ \\
\hline $\begin{array}{l}\text { Cerebrovascular } \\
\text { accident }\end{array}$ & 0 & $2(0.3)$ \\
\hline Seizure & 0 & $1(0.1)$ \\
\hline Gastrointestinal bleed & 0 & $3(0.4)$ \\
\hline
\end{tabular}

PAS, Pulmonary artery systolic pressure. *Some patients are counted in more than 1 category.

has yet to clearly define what cohort of patients will most or least benefit from this operation and which subset of patients will be most prone to perioperative complications and short-term mortality. To this end, we sought to examine whether patients with extremely high pulmonary artery pressures experience greater perioperative morbidity-mortality and whether pulmonary endarterectomy in these patients results in reduction of pulmonary vascular resistance to normal or near-normal levels.

We have 3 major conclusions from this study. First, patients with preoperative pulmonary artery pressures exceeding $100 \mathrm{~mm} \mathrm{Hg}$ are, in general, a more ill class of preoperative patients than individuals with less extreme forms of this disease. This is reflected in the proportion of patients with pulmonary artery systolic pressures of greater than $100 \mathrm{~mm} \mathrm{Hg}$ in high NHYA functional classes and greater numbers of these individuals requiring hospitalization before surgical intervention. Second, patients with extreme forms of thromboembolic pulmonary hypertension can satisfactorily undergo this operation with hemodynamic benefit that is immediate and curative. Third, although survival rates for patients with markedly increased pulmonary artery pressures are slightly less than for patients with less severe pulmonary hypertension, pulmonary endarterectomy in this patient population is still superior to lung transplantation or heart-lung transplantation. Our institutional survival rates after pulmonary endarterectomy in patients with extreme pulmonary hypertension $89.2 \%$ in the perioperative period in this study and approximately $75 \%$ at 5 years ${ }^{21}$ ) are superior to survival rates for patients undergoing lung or heart-lung transplantation for this disease, as reported in the 2004 Annual Report of the US Organ Procurement and Transplantation Network (74\% at 3 months and $39 \%$ at 5 years for single- and double-lung transplantation; $80 \%$ at 3 months and $48 \%$ at 5 years after heart-lung transplantation for pulmonary hypertension). ${ }^{22}$

In this study we did find that patients whose preoperative pulmonary artery pressures exceeded $100 \mathrm{~mm} \mathrm{Hg}$ were on average more debilitated before surgical intervention, had longer postoperative ICU stays, and manifested more major postoperative complications. Patients with a large diminution in pulmonary artery pressure after surgical intervention had, in general, a higher incidence of reperfusion injury to the lung, requiring longer periods of postoperative ventilatory support. For both groups 1 and 2, failure to decrease pulmonary artery systolic pressure at the time of the operation was the single factor most predictive of in-hospital mortality. Reperfusion injury, pneumonia, and acute renal failure were the complications most associated with prolonged periods of hospitalization.

Several lines of evidence suggest that increased pulmonary arterial pressures in chronic thromboembolic pulmonary hypertension are the result of both vascular obstruction and remodeling of small distal pulmonary arterioles in nonoccluded areas, similar to that seen in primary pulmonary hypertension. These include (1) an inexact correlation between the amount of central obstruction and the degree of pulmonary hypertension, ${ }^{23}$ (2) pathologic evidence of pulmonary arteriolar vasculopathy with medial hyperplasia and hypertrophy in the lungs of patients with thromboembolic disease, ${ }^{24,25}$ (3) redistribution of pulmonary blood flow after pulmonary endarterectomy from nonoccluded to newly endarterectomized vascular beds ${ }^{26}{ }^{2}$ (4) cases of worsening pulmonary hypertension in the absence of recurrent thromboemboli, ${ }^{27}$ and (5) persistent pulmonary hypertension despite successful endarterectomy in approximately $5 \%$ of patients. ${ }^{14}$

We have found that one of the largest risk factors for operation remains the degree of operability, as assessed by pulmonary artery pressure and pulmonary vascular resistance. Patients with high pulmonary artery pressures and angiographic signs of pulmonary vascular obstruction have favorable outcomes after this operation. However, high pulmonary artery pressures with few gross obstructive changes on angiography signals secondary small-vessel vasculopathy that is not amenable to surgical intervention. Pulmonary endarterectomy in this subset of patients results in persistent postoperative pulmonary hypertension that hinders recovery. Arteriolar-capillary vasculopathy represents either undiagnosed primary pulmonary hypertensive changes or small-vessel remodeling that occurs with redistribution of 
pressure or flow over time from mechanically occluded vascular beds to open pulmonary networks. Interestingly, we have found that small-vessel disease is not homogenous within the pulmonary vasculature of patients with thromboembolic disease. Arteriolar-capillary medial hyperplasiahypertrophy most often occurs in open pulmonary vascular beds that have not been obstructed by proximal thromboembolic disease.

We appreciate that cardiac remodeling after pulmonary endarterectomy is not complete in the perioperative period and that our results reflect only early hemodynamic outcome and survival. Long-term follow-up in our patient population is ongoing but challenging because of the fact that patients in this study were referred for surgical intervention from 10 countries (Great Britain, Australia, New Zealand, Canada, Belgium, Mexico, Brazil, France, Japan, and Italy) and more than 30 states. It is our impression that in patients undergoing pulmonary endarterectomy, longterm mortality is not influenced by recurrent pulmonary hypertension unless (1) new untreated pulmonary emboli occur or (2) the pulmonary endarterectomy was unsuccessful because of a lack of thromboembolic material in the proximal pulmonary arterial tree and the undiagnosed presence of microvascular arteriopathy. We believe that no patient should be denied pulmonary endarterectomy solely on the basis of the severity of preoperative disease. Indeed, the subset of patients with extreme forms of pulmonary hypertension may benefit the most from this operation.

\section{References}

1. Lewczuk J, Piszko P, Jagas J, Porada A, Wojciak S, Sobkowicz B, et al. Prognostic factors in medically treated patients with chronic pulmonary embolism. Chest. 2001;119:818-23.

2. Riedel M, Stanek V, Widimsky J, Prerovsky I. Longterm follow-up of patients with pulmonary thromboembolism: late prognosis and evolution of hemodynamic and respiratory data. Chest. 1982;81:151-8.

3. Thistlethwaite PA, Jamieson SW. Tricuspid valvular disease in the patient with chronic pulmonary thromboembolic disease. Curr Opin Cardiol. 2003;18:111-6.

4. Menzel T, Kramm T, Wagner S, Mohr-Kahaly S, Mayer E, Meyer J. Improvement of tricuspid regurgitation after pulmonary thromboendarterectomy. Ann Thorac Surg. 2002;73:756-61.

5. D'Armini AM, Cattadori B, Monterosso C, Klersy C, Emmi V, Piovella $\mathrm{F}$, et al. Pulmonary thromboendarterectomy in patients with chronic thromboembolic pulmonary hypertension: hemodynamic characteristics and changes. Eur J Cardiothorac Surg. 2000;18:696-702.

6. Masuda M, Nakajima N. Our experience of surgical treatment for chronic pulmonary thromboembolism. Ann Thorac Cardiovasc Surg. 2001;7:261-5.

7. Tscholl D, Langer F, Wendler O, Wilkens H, Georg T, Schafers HJ. Pulmonary thromboendarterectomy-risk factors for early survival and hemodynamic improvement. Eur J Cardiothorac Surg. 2001;19: 771-6.

8. Gladwin MT, Sachdev V, Jison ML, Shizukuda Y, Plehn JF, Minter K, et al. Pulmonary hypertension as a risk factor for death in patients with sickle cell disease. $N$ Engl J Med. 2004;350:886-95.

9. Sadeghi HM, Kimura BJ, Raisinghani A, Blanchard DG, Mahmud E, Fedullo PF, et al. Does lowering pulmonary arterial pressure eliminate severe functional tricuspid regurgitation? Insights from pulmonary thromboendarterectomy. J Am Coll Cardiol. 2004;44:126-32.
10. Jamieson SW, Kapelanski DP. Pulmonary endarterectomy. Curr Prob Surg. 2000;37:165-252.

11. Pengo V, Lensing AW, Prins MH, Marchiori A, Davidson BL, Tiozzo $\mathrm{F}$, et al. Incidence of chronic thromboembolic pulmonary hypertension after pulmonary embolism. $N$ Engl J Med. 2004;350:2257-64.

12. Thistlethwaite PA, Madani M, Jamieson SW. Pulmonary thromboendarterectomy surgery. Cardiol Clin. 2004;22:467-78.

13. Jamieson SW, Kapelanski DP, Sakakibara N, Manecke GR, Thistlethwaite PA, Kerr KM, et al. Pulmonary endarterectomy: experience and lessons learned in 1,500 cases. Ann Thorac Surg. 2003;76:1457-64.

14. Thistlethwaite PA, Mo M, Madani MM, Deutsch R, Blanchard D, Kapelanski DP, et al. Operative classification of thromboembolic disease determines outcome after pulmonary endarterectomy. J Thorac Cardiovasc Surg. 2002;124:1203-11.

15. Kim NH, Fesler P, Channick RN, Knowlton KU, Ben-Yehuda O, Lee $\mathrm{SH}$, et al. Preoperative partitioning of pulmonary vascular resistance correlates with early outcome after thromboendarterectomy for chronic thromboembolic pulmonary hypertension. Circulation. 2004;109:18-22.

16. Nagaya N, Ando M, Oya H, Ohkita Y, Kyotani S, Sakamaki F, et al. Plasma brain natriuretic peptide as a noninvasive marker for efficacy of pulmonary thromboendarterectomy. Ann Thorac Surg. 2002;74: $180-4$.

17. Dartevelle P, Fadel E, Chapelier A, Macchiarini P, Cerrina J, Parquin $\mathrm{F}$, et al. Angioscopic video-assisted pulmonary endarterectomy for post-embolic pulmonary hypertension. Eur J Cardiothorac Surg. 1999;16:38-43.

18. Kramm T, Mayer E, Dahm M, Guth S, Menzel T, Pitton M, et al. Long-term results after thromboendarterectomy for chronic pulmonary embolism. Eur J Cardiothorac Surg. 1999;15:579-84.

19. Zoia MC, D’Armini AM, Beccaria M, Corsico A, Fulgoni P, Klersy C, et al. Mid term effects of pulmonary thromboendarterectomy on clinical and cardiopulmonary function status. Thorax. 2002;57:608-12.

20. Hagl C, Khaladj N, Peters T, Hoeper MM, Logemann F, Haverich A, et al. Technical advances of pulmonary thromboendarterectomy for chronic thromboembolic pulmonary hypertension. Eur J Cardiothorac Surg. 2003;23:776-81.

21. Archibald CJ, Auger WR, Fedullo PF, Channick RN, Kerr KM, Jamieson SW, et al. Long-term outcome after pulmonary thromboendarterectomy. Am J Respir Crit Care Med. 1999;160:523-8.

22. 2004 Annual report of the US Organ Procurement and Transplantation Network and the Scientific Registry of Transplant Recipients: transplant data 1994-2003. Department of Health and Human Services, Health Resources and Services Administration, Healthcare Systems Bureau, Division of Transplantation, Rockville, Md; United Network for Organ Sharing, Richmond, Va; University Renal Research and Education Association, Ann Arbor, Mich; 2005.

23. Dartevelle P, Fadel E, Mussot S, Chapelier A, Herve P, de Perrot M, et al. Chronic thromboembolic pulmonary hypertension. Eur Respir J. 2004;23:637-48.

24. Moser KM, Bloor CM. Pulmonary vascular lesions occurring in patients with chronic major vessel thromboembolic pulmonary hypertension. Chest. 1993;103:685-92.

25. Du L, Sullivan CC, Chu D, Cho AJ, Kido M, Wolf PL, et al. Signaling molecules in nonfamilial pulmonary hypertension. $N$ Engl $\mathrm{J}$ Med. 2003;348:500-9.

26. Azarian R, Wartski M, Collignon MA, Parent F, Herve P, Sors H, et al. Lung perfusion scans and hemodynamics in acute and chronic pulmonary embolism. J Nucl Med. 1997;38:980-3.

27. Moser KM, Metersky ML, Auger WR, Fedullo PF. Resolution of vascular steal after pulmonary thromboendarterectomy. Chest. 1993; 104:1441-4.

\section{Discussion}

Dr David A. Fullerton (Denver, Colo). I have 3 questions for you. Your data clearly show that those patients with the highest degrees of pulmonary hypertension probably benefit the most from this operation and the operation can be done safely and effectively. However, as you have alluded to both with your results and in your 
manuscript, this clearly is a higher risk group of patients that had a greater length of stay, more complications, and higher degrees of reperfusion injury. Can you share with us some of the insights that your group has learned and how you need to optimize the care of these patients? Specifically, I am interested in whether you have any methods for trying to control the reperfusion injury, acknowledging it will be greater now that you understand that. But is there anything one can do to attenuate it at the time of surgery?

Dr Thistlethwaite. Thank you very much for your question. Reperfusion injury is the Achilles heel of pulmonary endarterectomy and it occurs in somewhere between $10 \%$ and $20 \%$ of all patients who undergo this operation. Unfortunately, there is not a clear correlation between worse reperfusion injury and the various gradations of pulmonary artery pressure. It bears out when you are looking at large groups in terms of extreme pulmonary hypertension versus less so, but there is no clear-cut 1:1 correlation. We do not have any tricks up our sleeve for dealing with this problem. Our care is mostly supportive. We provide longer periods of intubation, aggressive diuresis, but nothing more than what would be standard for other cardiac operations.

Dr Fullerton. Cardiac output was basically the same before and after the operation in both groups of patients. Acknowledging that right ventricular afterload is so much higher in your experimental group and that there was a greater diminution in pulmonary arterial pressure as a result of the operation, I was curious that cardiac output in your group of interest did not rise to a much higher degree than in the other group. Did that catch your eye as well and do you have any insight into that?

Dr Thistlethwaite. It is hard to draw conclusions about improvement in cardiac output in this set of patients because there is a wide range of preoperative pulmonary artery pressures and pulmonary vascular resistances studied. I would parenthetically say that most of the patients that are referred to us for this operation have normal left ventricular function, and those who do not (for example, the ones who need concomitant coronary or mitral valve procedures) were excluded from this study.

Dr Fullerton. Last, I know that your group does not address the tricuspid valve at the time of surgery. Available data suggest that it is uncommon that further interventions on the tricuspid valve are necessary. However, I am still struck by the fact that at least early on, despite a large reduction in pulmonary arterial pressure, the pulmonary artery pressures are still elevated. Is there any particular group that may ultimately require some attention to the tricuspid valve, or is it fair to say that universally they all get better and are basically normal?

Dr Thistlethwaite. You highlight a very important point in that remodeling of the right ventricle is not complete at the time of surgery but continues afterward. Certainly, tricuspid valve function would be an interesting thing to look at during longer term follow-up on our patients. I would say, however, that this is one system in which a valvular problem is completely reversed by an operation that does not involve surgery on the valve. I cannot remember the last time we have had to do any sort of tricuspid valve procedure in these patients, and the restoration of function, to a degree that no intervention is needed, is immediate.

Unidentified speaker. Have you some idea of the long-term results and have you made any attempt to match these groups with propensity matching or Cox hazard ratio to see whether your higher risk group is the one that may have the best results if it had been matched. Have you done this analysis at all and can you give us something about long-term results?

Dr Thistlethwaite. With regard to long-term results, our pulmonary endarterectomy registry has been in effect for 8 years and so long-term results will be forthcoming. This has been particularly difficult because, in this study alone, the patients referred to us have come from more than 15 countries and more than 40 states. Long-term follow-up has been somewhat challenging.

We have not attempted to determine statistical analysis matching propensity scores. 